\title{
MEIO AMBIENTE, DIREITO DE ENERGIA E ARBITRAGEM ${ }^{1}$
}

\author{
Cristiana Nepomuceno de Sousa SOARES ${ }^{1}$
}

Magno Federici GOMES ${ }^{2}$

\begin{abstract}
${ }^{1}$ Bacharel em Ciências Biológicas pela Pontifícia Universidade Católica de Minas Gerais. Bacharel em Direito pela Pontifícia Universidade Católica de Minas Gerais. Pós-graduada em Gestão Pública pela UFOP. Advogada. Currículo Lattes: <http://lattes.cnpq.br/4649083267216613>. Endereço eletrônico: cristiananepomuceno@ gmail.com

${ }^{2}$ Pós-doutor em Direito Público e Educação pela Universidade Nova de Lisboa-Portugal. Pós-doutor em Direito Civil e Processual Civil, Doutor em Direito e Mestre em Direito Processual, pela Universidad de Deusto-Espanha. Mestre em Educação pela PUC Minas. Professor do Mestrado Acadêmico em Direito Ambiental e Sustentabilidade na Escola Superior Dom Helder Câmara. Professor Adjunto da PUC Minas e Professor Titular licenciado da Faculdade de Direito Arnaldo Janssen. Advogado Sócio do Escritório Raffaele \& Federici Advocacia Associada. Integrante dos grupos de pesquisa: Regulação Ambiental da Atividade Econômica Sustentável (REGA)/CNPQ-BRA, Centro de Investigação \& Desenvolvimento sobre Direito e Sociedade (CEDIS)/FCT-PT e Núcleo de Estudos sobre Gestão de Políticas Públicas (NEGESP)/CNPQ-BRA. ORCID: <http://orcid.org/0000-0002-4711-5310>. Currículo Lattes:
\end{abstract} <http://lattes.cnpq.br/1638327245727283>. Endereço eletrônico: federici@pucminas.br

\section{Recebido em: 28/10/2016 - Aprovado em: 22/08/2017 - Disponibilizado em: 30/12/2017}

\begin{abstract}
RESUMO
A energia, considerada também um bem ambiental, se desenvolveu muito nos últimos tempos, juntamente com a sustentabilidade e a proteção ambiental. A arbitragem veio a promover, muitas vezes, decisões mais céleres, técnicas e sigilosas. Entretanto, apesar das vantagens desta solução extrajudicial de controvérsias, o resultado nem sempre agrada aos envolvidos. Assim, as sentenças arbitrais acabam sendo discutidas no Poder Judiciário. O problema a ser resolvido é a possibilidade ou não de arbitragem em direito de energia. A metodologia usada foi a teórico-documental, com a técnica dedutiva. Concluiu-se que a arbitragem não atinge plenamente a todos os bens, apenas os patrimoniais disponíveis, podendo ser parcialmente utilizada em direito de energia.
\end{abstract}

Palavras-chave: Bem ambiental; Direito de energia; Lei da Arbitragem; Arbitragem e energia.

\section{ENVIRONMENT, ENERGY LAW AND ARBITRATION}

\section{ABSTRACT}

Energy, also considered an environmental good, has developed a great deal in recent times, along with sustainability and environmental protection. More often than not, arbitration came to solve the need for rapid, more technical and sensitive decisions. Despite the advantages of this dispute settlement, the result not always pleases those involved. Thus, these decisions are eventually taken to Court for the final word. The problem to be solved is whether or not the Arbitration Law of energy. The methodology used was the theoretical and documentary, with the deductive technique. It was concluded that arbitration does not reach fully to all goods, only the balance available and can be partially used in the Energy law.
\end{abstract}

Keywords: Environmental good; Energy law; Arbitration Law; Arbitration and energy.

\footnotetext{
${ }^{1}$ Trabalho financiado pelo Edital $n^{\circ}$ 05/2016 (Projeto $n^{\circ}$ FIP 2016/11173-S2) do FIP/PUC MINAS, resultante dos Grupos de Pesquisas (CNPQ): Regulação Ambiental da Atividade Econômica Sustentável (REGA), NEGESP e CEDIS (FCT-PT). 


\section{INTRODUÇÃO}

O presente trabalho faz uma referência aos bens ambientais e sua importância para a humanidade e o mundo atual. Ao citar o bem ambiental, refere-se também a energia, que tem papel fundamental na vida do homem, desde os seus primórdios da vida na terra.

Mostra as fases da energia elétrica até chegar ao consumidor final e cita os tipos de energia. Faz-se, ainda, um breve histórico do setor, até chegar ao momento atual, passando inclusive pela Constituição da República de 1988 (CR/1988) e por leis específicas.

Aborda-se a multiplicação de conflitos ante o crescimento do setor energético. Ao mesmo tempo, com o aumento dos processos judiciais, uma resposta rápida e técnica muitas vezes é extremamente demorada, o que se contrapõe à resposta imediata que exige um conflito nesse campo. Nesse sentido, menciona a lei da arbitragem e suas finalidades, fazendo, por fim a interação entre a energia e a arbitragem.

A problemática do presente artigo é mostrar a importância dos dois assuntos e questionar eventuais limitações à arbitragem no Direito de energia. A arbitragem realmente veio para solucionar todas as controvérsias?

No trabalho, há referência ao bem ambiental, incluindo entre ele a energia. Falase da energia e da arbitragem e, depois, relaciona estes dois itens.

A metodologia usada foi a teóricodocumental, com a técnica dedutiva.

\section{BEM AMBIENTAL}

Desde a formação do mundo, o meio ambiente faz parte da vida humana, até mesmo porque ele engloba fatores bióticos e abióticos. Hoje, água, fauna e flora são objetos de proteção jurídica normativa.

Por algum tempo, numa visão antropocêntrica, o homem colocava o meio ambiente em segundo plano, até que passou a ter consciência que os recursos naturais são finitos, e não infinitos como antes se acreditava e o que implicava abusos contra os mesmos. Assim, deixa o homem de ser o centro e passa estar ao lado, com a conscientização de que ele também pertence ao meio ambiente e não o contrário.

Deste modo, com a mudança de sua visão, "o homem tem procurado acertar nossa situação de perigo em que se envolveu, visando à sua própria sobrevivência" (COSTA, 2010, p. 11).

Com a CR/1988, "iniciou-se no Brasil uma nova categoria de bens: os bens de uso comum do povo e essenciais à sadia qualidade de vida" (PIRES, 2008, internet). Entretanto, estes não são bens públicos e nem privados.

O art. 225 da CR/1988 fixa a existência de uma norma vinculada ao meio ambiente ecologicamente equilibrado, reafirmando, ainda, que todos são titulares desse direito. (VASCONCELOS, 2015, internet). Segundo Fiorillo (2010), "não se reporta a uma pessoa apenas, mas sim a uma coletividade de pessoas indefinidas, o que 
demarca um critério transindividual, em que não se determinam os titulares do direito" (FIORILLO, 2010, p. 176).

Apesar de fazer referência explícita ao meio ambiente, a Constituição do Brasil não reconhece a natureza como sujeito de direitos, mas protege o meio ambiente (TOLENTINO, OLIVEIRA, 2015, p. 313).

Assim, relata o art. 225, caput, da CR/1988 que: "todos têm direito ao meio ambiente ecologicamente equilibrado, bem de uso comum do povo e essencial à sadia qualidade de vida, impondo-se ao Poder Público e à coletividade o dever de defendê-lo e preservá-lo para as presentes e futuras gerações" (BRASIL, 1988).

O autor (2010) ainda ressalta que o:

bem ambiental é, portanto, um bem de uso comum do povo, podendo ser desfrutado por toda e qualquer pessoa dentro dos limites constitucionais, e, ainda, um bem essencial à qualidade de vida. E para uma vida saudável, exigese a satisfação dos fundamentos democráticos da CR/1988, entre eles, a da dignidade da pessoa humana, conforme disposto no art. $1^{\circ}$, inciso III, da CR/1988 (FIORILLO, 2010, p. 176).

Considerado como direito de terceira dimensão, o Ministro do Supremo Tribunal Federal (STF), Celso de Mello, assim se posicionou no voto por ele proferido em relatoria do Mandado de Segurança (MS) $n^{\circ}$
22.164-SP, cuja causa versava sobre desapropriação agrária² .

2 Os preceitos inscritos no art. 225 da Carta Política
traduzem a consagração constitucional em nosso
sistema de direito positivo, de uma das mais
expressivas prerrogativas asseguradas às formações
sociais contemporâneas. Essa prerrogativa consiste no
reconhecimento de que todos têm direito ao meio ambiente ecologicamente equilibrado. Trata-se, consoante já proclamou o Supremo Tribunal Federal (RE 134.297-SP, Rel. Min. Celso Mello) de um típico direito de terceira geração que assiste, de modo subjetivamente indeterminado, a todo o gênero humano, circunstância essa que justifica a especial obrigação - que incumbe ao estado e a à própria coletividade- de defende-lo e de preserva-lo em benefício das presentes e futuras gerações, evitando-se deste modo, que irrompam, no seio da comunhão social, os graves conflitos intergeracionais marcados pelo desrespeito ao dever de solidariedade na proteção da integridade desse bem essencial de uso comum de todos quantos compõem o grupo social (BRASIL. Supremo Tribunal Federal. Tribunal Pleno. Mandado de Segurança $n^{\circ}$ 22.164-SP. EMENTA: Reforma agrária. Imóvel rural situado no pantanal matogrossense- Desapropriação - Sanção (CF, art. 184) Possibilidade - Falta de notificação pessoal e prévia do proprietário rural quanto a realização da vistoria (Lei n.8.629/93, art.2, par.2) - Ofensa ao postulado do Due Processo f Law (CF, art. 5, LIV_ Nulidade radical da declaração expropriatória - Mandado de segurança deferido. reforma agraria e devido processo legal. - O postulado constitucional do Due Process of Law, em sua destinação jurídica, também esta vocacionado a proteção da propriedade. Ninguém será privado de seus bens sem o devido processo legal (cf, art. 5., liv). A União Federal - mesmo tratando-se de execução e implementação do programa de reforma agraria - não esta dispensada da obrigação de respeitar, no desempenho de sua atividade de expropriação, por interesse social, os princípios constitucionais que, em tema de propriedade, protegem as pessoas contra a eventual expansão arbitraria do poder estatal. A cláusula de garantia dominial que emerge do sistema consagrado pela Constituição da Republica tem por objetivo impedir o injusto sacrifício do direito de propriedade. Função social da propriedade e vistoria efetuada pelo INCRA. A vistoria efetivada com fundamento no art. 2., par. 2. , da Lei n. 8.629/93 tem por finalidade especifica viabilizar o levantamento técnico de dados e informações sobre o imóvel rural, permitindo a união federal - que atua por intermédio do INCRA - constatar se a propriedade realiza, ou não, a função social que lhe e inerente. $O$ ordenamento positivo determina que essa vistoria seja precedida de notificação regular ao proprietário, em face da possibilidade de o imóvel rural que lhe pertence quando este não estiver cumprindo a sua função social - vir a constituir objeto de declaração expropriatória, para fins de reforma agraria. notificação previa e 
pessoal da vistoria. a notificação a que se refere o art. 2. , par. 2., da Lei n. 8.629/93, para que se repute valida e possa consequentemente legitima eventual declaração expropriatória para fins de reforma agraria, há de ser efetivada em momento anterior ao da realização da vistoria. essa notificação previa somente considerar-seá regular, quando comprovadamente realizada na pessoa do proprietário do imóvel rural, ou quando efetivada mediante carta com aviso de recepção firmado por seu destinatário ou por aquele que disponha de poderes para receber a comunicação postal em nome do proprietário rural, ou, ainda, quando procedida na pessoa de representante legal ou de procurador regularmente constituído pelo dominus. $\mathrm{O}$ descumprimento dessa formalidade essencial, ditada pela necessidade de garantir ao proprietário a observância da cláusula constitucional do devido processo legal, importa em vício radical. que configura defeito insuperável, apto a projetar-se sobre todas as fases subsequentes do procedimento de expropriação, contaminando-as, por efeito de repercussão causal, de maneira irremissível, gerando, em consequência, por ausência de base jurídica idônea, a própria invalidação do decreto presidencial consubstanciador de declaração expropriatória. pantanal mato-grossense (cf, art. 225, par. 4.) - Possibilidade jurídica de expropriação de imóveis rurais nele situados, para fins de reforma agraria. - A norma inscrita no art. 225, paragrafo 4., da constituição não atua, em tese, como impedimento jurídico a efetivação, pela União Federal, de atividade expropriatória destinada a promover e a executar projetos de reforma agraria nas áreas referidas nesse preceito constitucional, notadamente nos imóveis rurais situados no pantanal mato-grossense. a própria Constituição da Republica, ao impor ao poder público dever de fazer respeitar a integridade do patrimônio ambiental, não o inibe, quando necessária a intervenção estatal na esfera dominial privada, de promover a desapropriação de imóveis rurais para fins de reforma agraria, especialmente porque um dos instrumentos de realização da função social da propriedade consiste, precisamente, na submissão do domínio a necessidade de o seu titular utilizar adequadamente os recursos naturais disponíveis e de fazer preservar o equilíbrio do meio ambiente (CF, art. 186, II), sob pena de, em descumprindo esses encargos, expor-se a desapropriação-sanção a que se refere o art. 184 da lei fundamental. A questão do direito ao meio ambiente ecologicamente equilibrado - Direito de terceira geração - Princípio da solidariedade. - O direito a integridade do meio ambiente - Típico direito de terceira geração - Constitui prerrogativa jurídica de titularidade coletiva, refletindo, dentro do processo de afirmação dos direitos humanos, a expressão significativa de um poder atribuído, não ao individuo identificado em sua singularidade, mas, num sentido verdadeiramente mais abrangente, a própria coletividade social. enquanto os direitos de primeira geração (direitos civis e políticos) - que compreendem as liberdades clássicas, negativas ou formais - Realçam o princípio da liberdade e os direitos de segunda geração (direitos econômicos, sociais e culturais) - Que

\section{Loubet (2014) defende que o}

constituinte colocou o meio ambiente como

bem autônomo eminentemente relacional,

pois ao colocá-lo como ecologicamente

equilibrado reconheceu a necessidade de

interação entre os seus elementos (recursos

ambientais, como ar, água, solo, fauna, flora,

turismo, cultura e trabalho).

Fiorillo (2010) considerou que a

CR/1988 em diversos artigos determina serem

da União ou dos Estados os bens tipicamente

ambientais, como se extrai dos arts. 20,

incisos III, IV, V e VIII, e art. 26, incisos I, II

e III. São eles:

os lagos, rios e quaisquer correntes de água em terrenos de seu domínio, ou que banhem mais de um Estado, sirvam de limites com outros Países, ou se estendam a território estrangeiro ou dele provenham, bem como os terrenos marginais $\mathrm{e}$ as praias fluviais; as ilhas fluviais e lacustres nas zonas limítrofes com outros países; as praias marítimas; as ilhas oceânicas e as costeiras, excluídas, destas, as que contenham a sede de Municípios, exceto aquelas áreas afetadas ao serviço público e a unidade ambiental federal, e as

se identifica com as liberdades positivas, reais ou concretas - Acentuam o princípio da igualdade, os direitos de terceira geração, que materializam poderes de titularidade coletiva atribuídos genericamente a todas as formações sociais, consagram o princípio da solidariedade e constituem um momento importante no processo de desenvolvimento, expansão e reconhecimento dos direitos humanos, caracterizados, enquanto valores fundamentais indisponíveis, pela nota de uma essencial inexauribilidade. considerações doutrinarias. Rel. Min. Celso de Mello, Brasília, 30 out. 1995. Diário de Justiça da União, Brasília, 17 nov. 1995. Seção 01, p. 39206. 
referidas no art. 26, II; os recursos naturais da plataforma continental e da zona econômica exclusiva; os potenciais de energia hidráulica (BRASIL, 1988).

E os também mencionados no art. 26 da CR/1988:

como as águas superficiais ou subterrâneas, fluentes, emergentes e em depósito, ressalvadas, neste caso, na forma da lei, as decorrentes de obras da União; as áreas, nas ilhas oceânicas e costeiras, que estiverem no seu domínio, excluídas aquelas sob o domínio da União, Municípios ou terceiros; as ilhas fluviais e lacustres não pertencentes à União (BRASIL, 1988).

Conforme citado acima, a CR/1988 relaciona em seus artigos, os bens ambientais, incluindo a energia. $\mathrm{O}$ bem ambiental é considerado com um direito fundamental intergeracional e, portanto, indisponível. Eles são essenciais à vida de todos os seres vivos e são também matéria-prima para tantas outras atividades artificiais.

\section{ENERGIA}

Nesta interação do meio ambiente com outras áreas, está a energia, ou melhor, o direito de energia. Nesse sentido:

É o ramo do direito que tem por objeto as questões tangenciadas pela energia, controlando e regulando os conflitos entre

\begin{abstract}
desenvolvimento
socioeconômico, proteção ambiental

sustentabilidade $^{3}$, bem como seus reflexos nos processo produtivos (DIREITO..., s./d., internet).
\end{abstract}

\section{Em conformidade com ENERGIA} (s./d., internet), seria impossível falar de energia sem associá-la ao meio ambiente, pois toda a energia produzida é resultado da utilização e transformação das forças oferecidas pela natureza. A história da energia confunde-se com a história da humanidade. Desde a pré-história que o homem já utilizava o fogo. Há aproximadamente cento e cinquenta anos, tem-se usado para a geração de energia os combustíveis fósseis. A energia surge de diferentes formas, seja nuclear, elétrica, hidráulica, solar e eólica, sendo colocada na categoria de direito fundamental, vez que possibilita aos cidadãos a concretização de uma vida digna. Nesse sentido:

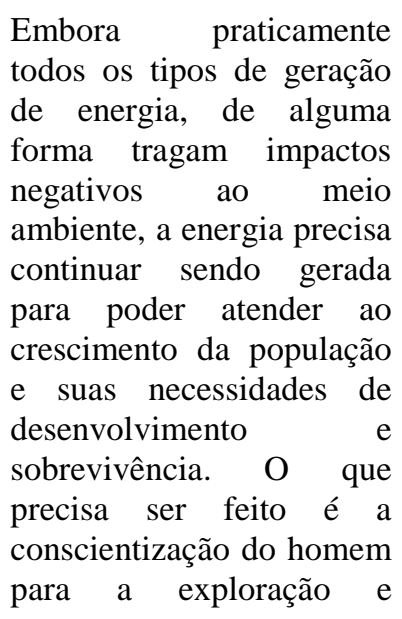

\footnotetext{
${ }^{3}$ Para analisar a ideia de desenvolvimento econômico em contraposição ao desenvolvimento sustentável e estudar um caso concreto, ver: BIZAWU; GOMES, 2016, p. 18-21.
} 
utilização de fontes de energia renováveis e de menor ou nenhum impacto para o meio ambiente, e também uma mudança cultural da forma de utilização da energia para o atendimento de suas necessidades, procurando utiliza-la de forma inteligente, racional $\mathrm{e}$ responsável (JERONYMO FILHO, s./d., internet).

No início dos anos 70, desponta o Direito de energia, ou Direito de eletricidade como era chamado. Foi definido por Alvares (1971) como:

[...] ramo do direito público que estuda e disciplina as relações jurídicas referentes ao emprego e utilização da energia depois de transformada em corrente elétrica.

Em consequência, constitui-se objeto do Direito de Eletricidade qualquer espécie de energia transformada, seja atômica ou mesma humana, que uma vez produzindo corrente elétrica passa a sofrer a informação e disciplina do no ramo do Direito (ALVARES, 1971, p. 27).

Continua fazendo a distinção entre energia e eletricidade:

[...] como a eletricidade é uma consequência de conversão da energia, então energia atômica, a energia hidráulica, a energia solar, a energia eólica, como raw energy, isto é, energia bruta, não trabalhada, para, se se mantiverem no seu campo particular e originário, não sofrem a disciplina do
Direito da Eletricidade, mas, uma vez transformadas em corrente elétrica, uma vez funcionando como eletricidade, passam ao campo do novo setor da ciência jurídica.

A energia proveniente do sol, vento e marés, conquanto estudada, possível é transformada, ainda não atingiu um estágio de aproveitamento competitivo com as fontes de combustíveis fósseis (carvão, petróleo) ou físsil (átomo), ou a hidráulica.

Mas, ao Direito de Eletricidade, portanto, o que importa substancialmente não é a fonte de energia, mas a sua conversão em corrente elétrica utilizada com repercussão em corrente elétrica utilizada, com repercussão econômica. Por isto, a energia atômica, a energia hidráulica e outras formas de energia só acidentalmente poderão ser objeto de consideração por parte do novo direito, como matéria de que haja relação aproximada (ALVARES, 1971, p. 28).

Antes de entrar no histórico do Direito de energia no Brasil, serão mencionados alguns conceitos básicos relativos às etapas que compõem o caminho da energia elétrica, desde a sua produção até a chegada ao consumidor final.

\subsection{A cadeia produtiva da energia elétrica}

Não existe na natureza a energia elétrica já de forma aproveitável. Seu aproveitamento acontece através de um ciclo 
cuja primeira etapa é a geração. Esta consiste, conforme ensina Di Pietro (2009), na conversão de:

[...] fontes primárias de energia em energia elétrica. A denominação dos tipos de energia elétrica leva em conta a fonte primária de energia utilizada na sua produção: térmica (gás, carvão, óleo etc.), hídrica, nuclear (modalidade especial de energia térmica) e renovável (eólica, solar etc.). Na década de 90, a energia elétrica era predominantemente oriunda das usinas hidrelétricas, responsáveis por cerca de $94 \%$ do total produzido, contra cerca de $5 \%$ de geração em usinas termelétricas e $1 \%$ em usinas nucleares (DI PIETRO, 2009, p. 341).

Leia-se:

Em tese, qualquer pessoa pode possuir uma unidade geradora de energia elétrica- no Brasil, como é sabido, há restrições para utilização dos cursos d’água, assim como para utilização de combustível nuclear - de modo que a geração admite a produção tanto em regime monopólio quanto em regime de competição (DI PIETRO, 2009, p. 341).

Uma vez produzida, é necessário transportar a energia até as proximidades dos centros consumidores, esta fase é a transmissão. Segundo Di Pietro (2009):
Como seria economicamente inviável (tendo em vista os custos de construção das torres e linhas de transmissão, centros de operação etc.) instaurar nesta etapa um regime de competição, com a construção de estruturas paralelas, a transmissão da energia é considerada monopólio natural (DI PIETRO, 2009, p. 341$)$.

Próxima dos centros consumidores, a energia elétrica precisa ser distribuída, levada às fábricas, hospitais, residências, esta fase é a distribuição. Como a transmissão, é também considerada monopólio natural, pois seria economicamente inviável duplicar as redes de transmissão (postes ou tubulação subterrânea, fiação e transformadores de pequeno porte, por exemplo).

Levada até os consumidores, a energia é entregue a eles, esta fase é a comercialização. Nesta etapa, qualquer um pode comprar energia elétrica das geradoras e, utilizando mediante pagamento a rede única de transmissão e distribuição, vendê-la aos consumidores finais, esta pode ser feita em regime de competição, conforme ensina $\mathrm{Di}$ Pietro (2009, p. 342).

Assim, são quatro as etapas da cadeia produtiva da energia: geração, transmissão, distribuição e comercialização, nas quais a segunda e a terceira são monopólios naturais. 


\subsection{Breve histórico}

Um breve relato da história da energia no Brasil, começando pela época do Império até chegar aos dias atuais:

Pode ser utilizada como
exemplo dessemomento de
desenvolvimento
energético a inauguração,
em 1879, da Estaça de
Ferro Central doBrasil, a
primeira instalação de
iluminação elétrica
permanentedo país. Em
1881, foi instalada a
primeira iluminação
externa pública do país...
Posteriormente, for
construída a primeira
hidrelétrica do país em
Diamantina, estado de
Minas Gerais, em 1883,em
afluente do rio
Jequitinhonha
(SANCHES, 2011, p. 41).

No início dos anos 50, houve períodos intermitentes de racionamento, em razão do excesso de demanda e de uma escassez de chuvas na região Sudeste.

Em 1961 foi criado o Ministério de Minas e Energia, e em 1962 a Eletrobrás.

Nos anos 70, prevaleceu o Direito de eletricidade em relação ao Direito de energia, que só ganhou conhecimento no início dos anos 90 .

Ainda no final dos anos 70, o Brasil mudou sua política econômica. Com isto, vieram vários planos para introduzir no País o regime jurídico da privatização.

Desta forma, nos últimos vinte anos do século XX, uma sucessão de “crises" suscitou questionamentos quanto à organização do Poder Público. Nesse sentido:

esse modelo de
Administração Pública
Gerencial emerge na
segunda metade do século
XX, como resposta, de um
lado, à expansão das
funções econômicas e
sociais do Estado e, de
outro, ao desenvolvimento
tecnológico e à
globalização da economia
mundial, uma vez que
ambos deixaram à mostra
os problemas associados à
adoção do modelo anterior
(GUERRA, 2011, p. 17,
nota 21)

A queda do muro de Berlim, em 1980, reacendeu as esperanças das cruzadas do Liberalismo, que passaram a sustentar, como se fosse um dogma, a divisa, a salvação do mundo está na privatização e que a presença do Estado no domínio econômico implicaria lentidão e ineficiência na prestação dos serviços.

Desta forma, o formalismo e o rigor técnico burocrático deram lugar ao o novo modelo administrativo.

O neoliberalismo provocou uma reformulação do papel do Estado, a partir do princípio da subsidiariedade2, segundo o qual o Estado só deveria intervir onde houvesse a incapacidade de o mercado resolver por si só o atendimento do interesse público (CAMARGO, 2000, p. 09). Ocorre, então, a diminuição dos limites estatais, com o fenômeno da "privatização do Direito Público". 
O Brasil dos anos 80 se adequou a uma nova forma de modelo de Estado, baseou-se em um modelo regulador, e saiu da esfera do monopólio do Estado, como a era de Getúlio Vargas e o regime militar.

Além do Brasil, o mundo também mudou, desenhando à época uma nova estrutura de Estado. $\mathrm{O}$ antigo modelo interventor passou por assumir um modelo de regulação, situado entre dois outros econômico-sociais: o liberal e o comunista/socialista. Mas, o Estado Regulador pendeu ora mais para o lado liberal, ora mais para o lado social, dependendo das diretrizes que nortearam o modelo regulatório adotado por cada País. Sua origem foi assim relatada:

Em resumo, com a crise e falência do Estado Desenvolvimentista iniciado por Getúlio Vargas no Brasil e que resiste até meados da década de 80, surge uma nova forma de atuação do Estado, tanto no âmbito nacional, quanto no internacional. $\mathrm{O}$ modelo intervencionista gerou um crescimento da dívida, o que estrangulou o Estado, que como consequência não conseguiu mais manter o mesmo nível de investimento. Logo, com vistas a diminuir a dívida pública e fornecer algum tipo de liberdade econômica, nasce o "Estado Regulador" (COIMBRA, 2001, internet).

O setor elétrico, nos anos 90, passou por mudanças significativas. Em 1993, a Lei $\mathrm{n}^{\mathrm{o}} 8.631 / 1993$, entre outras providências, concedeu a fixação dos níveis das tarifas para o serviço público de energia elétrica e extinguiu o regime de remuneração garantida. Em 1995, foi promulgada a Lei $\mathrm{n}^{\circ}$ 8.987/1995, que dispôs "sobre o regime de concessão e permissão da prestação de serviços públicos previsto no art. 175 da CR/1988, e deu outras providências" (BRASIL, 1995). E, ainda no mesmo ano, teve-se, ainda, a promulgação da Lei no 9.074/1995, que "estabeleceu normas para outorga e prorrogações das concessões e permissões de serviços públicos e deu outras providências" (BRASIL, 1995).

Surgia, desta forma, uma maior flexibilização e introdução da competição no setor elétrico. A reestruturação do setor foi marcada pela criação da Agência Nacional de Energia Elétrica (ANEEL), a partir da Lei no 9.427/1996.

\subsection{A Constituição da República de 1988 e a energia}

A CR/1988 foi promulgada em uma época de mudanças para o neoliberalismo.

A CR/1988 tratou da energia em alguns artigos, como no art. 20, inciso VIII, segundo o qual "são bens da União os potenciais de energia hidráulica" (BRASIL, 1988). No art. 22, inciso IV, dispôs que compete privativamente à União legislar sobre a energia. No art. 175 , disciplinou "sobre o regime de concessão ou permissão, 
sempre através de licitação, de prestação de serviços públicos" (BRASIL, 1988). Já no art. 176 define que "os potenciais de energia hidráulica constituem propriedade distinta da do solo, para efeito de exploração ou aproveitamento" (BRASIL, 1988). E declara no art. 177, inciso I, que o gás natural é monopólio da União.

Segundo Campos (2010), "para incentivar a exploração de energia renovável de capacidade reduzida, a Constituição dispensa a atividade de qualquer autorização ou concessão" (CAMPOS, 2010, p. 15). E menciona:

\begin{abstract}
a União é competente para a exploração direta ou mediante autorização, concessão ou permissão de serviços e instalações de energia elétrica, bem como aproveitamento dos potenciais de energia hidráulica, articulando com o estado-membro em cujo território se localize a fonte de energia (letra $b$, inciso XII do artigo 21, CF) (CAMPOS, 2010, p. 16).
\end{abstract}

Esclarece, ainda, que:

esse dispositivo prevê, expressamente, a possibilidade de a União outorgar, mediante mera autorização, a geração de energia elétrica ao produtor independente, que, em última análise, nada mais é do que um serviço de geração agregado a uma instalação de conversão elétrica.

A tutela constitucional de preservação do meio ambiente impôs que a

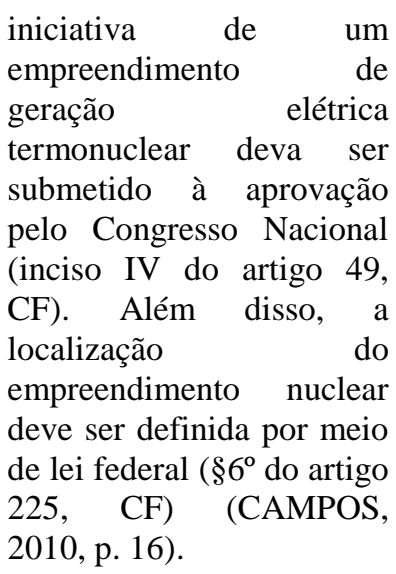

A CR/1988 trata das formas da exploração da energia, ou seja, por autorização, permissão ou concessão, contratos administrativos de delegação de atividades públicas ao particular.

\section{ARBITRAGEM}

Definida como um método privado de solução de conflitos fora do Poder Judiciário em que um ou mais árbitros emitem decisões ágeis e técnicas, as sentenças arbitrais, com força de sentença judicial.

É caracterizada pela informalidade e só pode ser usada pela vontade das partes envolvidas. Estas mesmas definem o prazo para a tomada das decisões e ainda elegem um ou mais árbitros imparciais e experientes na área da disputa, para analisarem o caso. Entretanto, só os conflitos inerentes a direitos patrimoniais podem estar submetidos à arbitragem.

A Lei no 9.307/1996 menciona no art. 25 que se houverem direitos indisponíveis na controvérsia, o juízo arbitral deveria remeter o conflito para o Poder Judiciário. Ocorre que 
tal dispositivo foi revogado pela Lei no $13.129 / 2015$.

Por sua vez, foi aprovada uma nova Lei de Mediação, Lei no 13.140/2015, que em seu art. $3^{\circ}$ determina a possibilidade de utilização da mediação para compor "direitos indisponíveis que admitam transação", desde que seja "homologado em Juízo, exigida a oitiva do Ministério Público" (BRASIL, 2015). Nota-se que o tema extrapola os limites deste estudo, pois versa sobre o instituto da mediação judicial e extrajudicial para a consecução de auto composição entre as partes, não se confundindo com a arbitragem.

Apesar de informal, o procedimento é sigiloso, de modo a evitar a exposição pública de conflitos entre as partes, bem como possíveis danos à imagem e prejuízos.

A lei veio instituir a arbitragem entre as pessoas capazes de dirimir litígios relativos a direitos patrimoniais disponíveis e estabelece que as partes podem escolher qual o direito aplicável, quando não ferisse a ordem pública e a moralidade. Dentre os direitos indisponíveis não podem ser submetidos à arbitragem as questões de penal, tributário e direito de família.

A Lei no 9.307/1996 previa a cláusula compromissória, que é a convenção através da qual as partes em um:

contrato comprometem-se a submeter à arbitragem os litígios que possam vir a surgir relativamente a tal contrato. Esta cláusula deveria ser estipulada por escrito, podendo estar inserta no próprio contrato ou em documento apartado que a ele se refira. Nos contratos de adesão, a cláusula compromissória só terá eficácia se o aderente tomar a iniciativa de instituir a arbitragem ou concordar, expressamente, com a sua instituição, desde que por escrito em documento anexo ou em negrito, com a assinatura ou visto especialmente para essa cláusula (BRASIL, 1996).

Segundo voto do Ministro João Otávio

Noronha:

[...] 1- Cláusula compromissória é o ato por meio do qual as partes contratantes formalizam seu desejo de submeter à arbitragem eventuais divergências ou litígios possíveis de ocorrer ao longo da execução da avença. Efetuado o ajuste, que só pode ocorrer em hipóteses envolvendo direitos disponíveis, ficam os contratantes vinculados à solução extrajudicial da pendência.

2- A eleição da cláusula compromissória é causa da extinção do processo sem julgamento de mérito, nos termos do art. 267, inciso VII, do Código de Processo Civil.

3- São válidos e eficazes os contratos firmados pelas sociedades de economia mista exploradoras de atividade econômica de proteção ou comercialização de bens ou prestação de serviços $\left(\mathrm{CF}\right.$, art. $\left.175, \S 1^{\circ}\right)$ que estipulem cláusula compromissória submetendo à arbitragem eventuais litígios decorrentes do ajuste (BRASIL. Superior 
Tribunal de Justiça. Segunda Turma. Embargos de Declaração no Recurso Especial no 612.439-RS. Rel. Min. João Otávio de Noronha, Brasília, 17 maio 2007. Diário de Justiça da União, Brasília, 06 jun. 2007. Disponível em: <http://www.stj.gov.br>.

Acesso em:26 maio 2016).

Se esta não dispusesse sobre a nomeação de árbitros, competiria ao magistrado, prévia oitiva das partes, estabelecer sobre o assunto, podendo nomear um único árbitro para a solução do litígio.

Caso, o autor não comparecesse a audiência, o processo seria extinto sem resolução do mérito. Se não houvesse acordo prévio:

para instituir a arbitragem, a parte interessada manifestaria à outra parte sua intenção de dar início à arbitragem, por via postal ou por outro meio qualquer de comunicação, mediante comprovação de recebimento, convocandoa para, em dia, hora e local certos, firmar o compromisso arbitral (BRASIL, 1996).

A sentença que acolher a pretensão autoral valerá como compromisso arbitral, consistente na convenção por meio da qual os interessados submetem o litígio à arbitragem de um ou mais árbitros, podendo ser classificada como judicial ou extrajudicial.

Com a reforma da lei, criou-se um cenário de escolha para a Administração Pública eleger a arbitragem para a solução de conflitos. Para a iniciativa privada, a arbitragem passa a representar importante mecanismo compensatório dos riscos políticos e de um ambiente de incertezas regulatórias, que hoje certamente influenciam negativamente o empreendedorismo voltado à geração de infraestrutura pública no País.

\section{ARBITRAGEM E ENERGIA}

No setor elétrico, a arbitragem, por conta das diversas vantagens que apresenta, vem se destacando como um relevante e eficaz mecanismo alternativo de solução de controvérsias, especialmente por sua celeridade, preservação do sigilo das partes envolvidas e elevado grau de expertise dos árbitros.

Pouco se fala, mas também é atribuição das agências reguladoras dirimir conflitos de interessas entre os agentes econômicos regulados. Em 27 de março de 2001, foi aprovada a Resolução Conjunta $n^{\circ}$ 002/2001 da ANEEL, ANATEL e ANP, através da qual "foi estabelecido o Regulamento Conjunto de Resolução de Conflitos das Agências Reguladoras dos Setores de Energia Elétrica, Telecomunicações e Petróleo", objetivando assegurar "a ampla, livre e justa competição e os benefícios aos usuários dos serviços" (BRASIL, 2001).

Instituída pela Lei $\mathrm{n}^{\mathrm{o}} 10.848 / 2004$, a Câmara de Comercialização de Energia Elétrica (CCEE) foi criada sob autorização e fiscalização da ANEEL, com o fito de 
viabilizar o comércio de energia no âmbito livre e regulado em substituição ao extinto Mercado Atacadista de Energia Elétrica MAE.

O estatuto social da CCEE aprovado pelos agentes da Câmara reunidos em assembleia geral, também trata da arbitragem em três artigos: (a) art. $8^{\circ}$, inciso IX: obrigação de adesão dos agentes à convenção arbitral; (b) art. $9^{\circ}$, inciso V: direito do agente de submeter eventuais conflitos ao Conselho de Administração da CCEE, à ANEEL ou à arbitragem; e (c) art. 40: os eventuais conflitos fundados nas relações estatutárias ou decorrentes da comercialização no âmbito da CCEE serão dirimidos pela via da arbitragem, no âmbito da Câmara de Arbitragem definida pela Assembleia Geral dos Agentes, sem prejuízo da atuação da ANEEL, em conformidade com CCEE (2014, internet).

A sentença arbitral que não for cumprida voluntariamente poderá ser objeto de execução, com a aplicação das disposições do Código de Processo Civil (CPC).

A recessão econômica estimula a busca por resolução de conflitos entre empresas em câmaras de arbitragem, de maneira a evitar litígios perante o Poder Judiciário.

Apesar de ser um meio rápido, sigiloso, informal e com possibilidade de solução amigável, há casos que, necessariamente, devem ser resolvidos no Poder Judiciário.
Como exemplo, traz-se à tona o caso Abengoa e a paulista Adriano Ornetto Agrícola. Esta arbitragem foi realizada em Nova York e envolvia:

A disputada começou em 4 de agosto de 2007, quando Adriano Ometto vendeu para a Abengoa as duas usinas sucroalcooleiras administradas pela Dedini Agro. $\mathrm{O}$ mercado brasileiro de açúcar e etanol estava em ascensão, o que levou ao preço de US\$ 327 milhões pelas unidades.

Adriano é Neto de Dovilio Ometto, que faleceu em 30 de agosto de 2007 e era controlador da Dedini Indústria de Base, que pediu recuperação judicial no mês passado. As duas 'Dedinis' eram independentes desde 2003. Com a virada do mercado, e após amargar prejuízos com o negócio devido a uma série de dívidas e processos trabalhistas, a Abengoa recorreu a um Tribunal Arbitral, nos EUA, pedindo indenização. A Adriano Ometto Agrícola calculou em US\$ 18 milhões o valor que poderia ressarcir os aportes feitos pela Abengoa nas usinas, mas $\mathrm{s}$ espanhola quis mais e levou o processo para o julgamento arbitral em Nova York.

Em novembro de 2011, segundo o Valor Econômico, o caso foi decidido, mas com uma indenização equivalente a 1 milhão de toneladas de açúcar (US\$ 100 milhões). Para a Corte Arbitral, houve fraude nas estimativas de potencial de moagem de cana das usinas apresentadas pela empresa brasileira, que somavam 7 milhões de toneladas por safra. 


\section{[...]}

Mas a Adriano Ometto recorreu à Justiça de Nova York, após verificar que o árbitro-presidente da causa, o americano David W. Rivkin, é sócio de um escritório (Debevoise \& Plimpton LLP) que recebeu US\$ 6,5 milhões de Abengoa. Um dos advogados mais prestigiados em Nova York, Rivkin é presidente da International Bar Association (IBA), organização que congrega ordens de advogados em vários países do mundo. Ao todo, a banca de Rivkin atuou em operações de cerca de US\$ 5 bilhões envolvendo a empresa espanhola.

Questionado nos autos do processo sobre a coincidência, Rivkin alegou que houve "erro administrativo". Segundo ele, "somente os nomes das partes originais do caso foram lançados no sistema de controvérsias" do escritório. Por esta razão, o nome de Abengoa não teria sido registrado, mas apenas a identificação do grupo ASA Bioenergy Holding AG. A Abengoa estaria dentro da sigla ASA e o advogado-árbitro não teria percebido. "Lamento esse erro administrativo", justificou (BRASILAGRO, 2015, internet).

Tal feito foi remetido ao STJ com o número SEC 9.412-US, em que a Asa Bioenergy Holding visava a receber $\mathrm{R} \$ 389$ milhões da Abengoa Bionergia Agrícola. Assim:

A Corte Especial do Superior Tribunal de Justiça (STJ) começou a julgar ontem a validade de arbitragem feita em Nova York que estabeleceu indenização de US\$ 100 milhões à espanhola Abengoa por problemas decorrentes da aquisição de usinas sucroalcooleiras que pertenciam ao empresário paulista Adriano Ometto. Por ora, foi proferido apenas o voto do relator, ministro Felix Fischer, favorável à homologação da decisão.

[...]

Sobre a parcialidade de Rivik, o relator afirmou que a Lei $\mathrm{n}^{\circ}$ 9.307, de 1996, que dispõe sobre a arbitragem no Brasil, estabelece que a parte que quiser tratar de impedimento de árbitro deve se pronunciar na primeira oportunidade após a instituição do procedimento. No caso, o pedido sobre a imparcialidade não foi acolhido no tribunal arbitral. E, posteriormente, a ação de anulação proposta na Justiça americana também foi julgada improcedente (OLIVON, 2015, internet).

A arbitragem realizada neste caso está analisando direitos patrimoniais disponíveis ${ }^{4}$, isto é, aqueles que seriam objeto de transação, apropriação, alienação e outro, conforme determina $\mathrm{o}$ art. $1^{\circ}$ da Lei.

Em relação aos direitos indisponíveis a lei atual nada menciona, foi revogado o art. 25 da Lei anterior que mencionava que estes deveriam ser remetidos pelo juízo arbitral ao Poder Judiciário.

Se o objeto do litígio da arbitragem determinado no seu art. $1^{\circ}$ explicita

${ }^{4} \mathrm{O}$ feito SEC 9.412-US está incluído na pauta de julgamento do Órgão Especial designada para 21/09/2016. 
claramente que só pode bens patrimoniais disponíveis, então pode-se concluir que os bens indisponíveis não podem ser arbitrados.

No julgamento de processo de recepção de decisão estrangeira (SE 5206), o STF considerou constitucional a antiga lei de arbitragem.

Ora, se a norma foi declarada constitucional pelo STF, então a arbitragem de bens indisponíveis seria inconstitucional. Resta, desta forma, na área de energia, a possibilidade de arbitragem apenas das concessionárias e permissionárias, naquilo aonde o interesse seria patrimonial disponível.

\section{CONSIDERAÇÕES FINAIS}

A energia, conhecida há muito e muito tempo, faz parte das relações humanas desde os primórdios.

Ao se falar em energia não se pode deixar de relacioná-la com o meio ambiente, especialmente no âmbito do desenvolvimento sustentável e da proteção ambiental.

$O$ direito de energia emergiu na década de 70 e era, primeiramente, conhecido como Direito da eletricidade. Ao final do século XX, com as mudanças ocasionadas pelo neoliberalismo, o setor elétrico passou por mudanças significativas.

A CR/1988 disciplinou o tema em seu texto, reservando alguns artigos para tanto.

Com o crescimento desta área, surgem também novos conflitos. Aliado a isso, tem-se a crescente demanda judicial, com a elevação do número de ações que tramitam no Poder Judiciário, o que impulsiona as formas alternativas de resolução de conflitos. Especialmente, uma mais célere, sigilosa e com conhecimentos mais específicos, a saber, a arbitragem.

Ocorre que, muitas vezes, também estas decisões não agradam aos envolvidos e o litígio acaba sendo levado ao Poder Judiciário para a última decisão acerca da controvérsia.

Com isto, percebe-se que embora seja um método muito eficaz para as partes, a arbitragem tem suas limitações, não se sobrepondo a via judicial para solução de conflitos.

A arbitragem no setor elétrico restringe-se somente aos conflitos entre concessionárias e permissionárias, só e tão somente nas questões de direitos patrimoniais disponíveis entre elas. As matérias indisponíveis, especialmente as relacionadas ao bem ambiental, somente podem ser apreciadas pelo Poder Judiciário, juntamente com as questões penais, tributárias e familiares não sujeitas à arbitragem.

\section{REFERÊNCIAS}

\section{ALVARES, Walter T. Estudos de direito da eletricidade. Belo Horizonte: IDE, 1971.}

BIZAWU, Kiwonghi; GOMES, Magno Federici. Oil exploitation at Virunga park as a threat to the environment and to endangered animal species. Veredas do Direito, Belo Horizonte, v. 13, n. 27, p. 11-29, set./dez. 2016. Disponível em: 
<http://www.domhelder.edu.br/revista/index. php/veredas/article/view/897>. Acesso em: 22 jun. 2017.

BRASILAGRO. Assessoria de Comunicação. Litígio entre Abengoa e Adriano Ometto: arbitragem nos EUA chega ao STJ.

Brasilagro: informação para ter opinião, Ribeirão Preto, 16 set. 2015. Disponível em: $<$ http://www.brasilagro.com.br/conteudo/litigi o-entre-abengoa-e-adriano-omettoarbitragem-nos-eua-chega-aostf.html\#.V9bxOlsrIdU>. Acesso em: 12 set. 2016.

BRASIL. ANEEL; ANATEL; ANP. Resolução Conjunta $n^{\circ} 002$ da ANEEL, ANATEL e ANP, de 29 mar. 2001. Aprova o Regulamento Conjunto de Resolução de Conflitos das Agências Reguladores dos Setores de Energia Elétrica, Telecomunicações e Petróleo. Diário Oficial da União, Brasília, 29 mar. 2001. Atualização até 25 ago. 2016. Disponível em:

$<$ http://www.anatel.gov.br/legislacao/resoluco es/resolucoes-conjuntas/85-resolucaoconjunta-2>. Acesso em: 07 set. 2016.

BRASIL. Constituição da República Federativa do Brasil, de 05 out. 1988. Diário Oficial da União, Brasília, 05 out. 1988. Disponível em:

<http://www.planalto.gov.br/ccivil_03/constit uicao/constituicaocompilado.htm>. Acesso em: 19 jun. 2016.

BRASIL. Lei n ${ }^{\circ}$ 8.631, de 4 mar. 1993. Dispõe sobre a fixação dos níveis das tarifas para o serviço público de energia elétrica, extingue o regime de remuneração garantida e dá outras providências. Diário Oficial da União, Brasília, 29 jan. 1993. Disponível em: <http://www.planalto.gov.br/ccivil_03/leis/L8 631.htm>. Acesso em: 26 maio 2016.

BRASIL. Lei no 8.987, de 13 fev. 1995. Dispõe sobre o regime de concessão e permissão da prestação de serviços públicos previsto no art. 175 da Constituição Federal e dá outras providências. Diário Oficial da União, Brasília, 14 fev. 1995. Disponível em:
<http:www.planalto.gov.br/ccivil_03/leis/L89 87.htm>. Acesso em: 26 maio 2016.

BRASIL. Lei $n^{\circ}$ 9.074, de 07 jul. 1995. Estabelece normas para outorga e prorrogações das concessões e permissões de outorga de serviços públicos e dá outras providências. Diário Oficial da União, Brasília, 08 jul. 1995. Disponível em: <http://www.planalto.gov.br/ccivil_03/leis/L9 074cons.htm>. Acesso em: 26 maio 2016.

BRASIL. Lei n ${ }^{\circ}$ 9.307, de 23 set. 1996. Dispõe sobre a arbitragem. Diário Oficial da União, Brasília, 23 set. 1996. Disponível em: <http://www.planalto.gov.br/ccivil_03/leis/L9 307cons, htm>. Acesso em: 26 maio 2016.

BRASIL. Lei $\mathrm{n}^{\circ}$ 13.140, de 26 jun. 2015. Dispõe sobre a mediação entre particulares como meio de solução de controvérsias e sobre a autocomposição de conflitos no âmbito da administração pública; altera a Lei no 9.469 , de 10 de julho de 1997, e o Decreto no 70.235 , de 6 de março de 1972; e revoga o $\S 2$ o do art. 6o da Lei no 9.469, de 10 de julho de 1997. Diário Oficial da União, Brasília, 29 jun. 2015. Disponível em: <http://www.planalto.gov.br/ccivil_03/_Ato2 015-2018/2015/Lei/L13140.htm>. Acesso em: 08 set. 2016.

BRASIL. Superior Tribunal de Justiça. Órgão Especial. Sentença Estrangeira Contestada (SEC) no 9412-US. Rel. Min. Felix Fischer, Brasília. Em julgamento. Disponível em: $<$ https://ww2.stj.jus.br/processo/pesquisa/?tip oPesquisa=tipoPesquisaNumeroRegistro\&ter $\mathrm{mo}=201302788725 \&$ totalRegistrosPorPagina $=40 \&$ aplicacao $=$ processos. $\mathrm{e}>$. Acesso em: 12 set. 2016.

BRASIL. Superior Tribunal de Justiça. Segunda Turma. Embargos de Declaração no Recurso Especial no 612.439-RS. Rel. Min. João Otávio de Noronha, Brasília, 17 maio 2007. Diário de Justiça da União, Brasília, 06 jun. 2007. Disponível em: <http://www.stj.gov.br>. Acesso em: 26 maio 2016. 
BRASIL. Supremo Tribunal Federal. Tribunal Pleno. Mandado de Segurança ${ }^{\circ}$ 22.164-SP. Rel. Min. Celso de Mello, Brasília, 30 out. 1995. Diário de Justiça da União, Brasília, 17 nov. 1995. Seção 01, p. 39206. Disponível em: <http://www.stf.gov.br>. Acesso em: 26 maio 2016.

CÂMARA DE COMERCIALIZAÇÃO DE ENERGIA ELÉTRICA (CCEE). Estatuto social consolidado após sua $59^{a}$ Assembleia Geral Extraordinária, realizada em 22 de outubro e 04 de novembro de 2014. ccee, São Paulo, 2014. Disponível em:

<https://ccee.org.br/ccee/documentos/CCEE_ 074748>. Acesso em: 07 set. 2016.

CAMARGO, Ricardo Antônio Lucas.

Agências de regulação no ordenamento jurídico-econômico brasileiro. Porto Alegre: Sérgio Antônio Fabris, 2000.

CAMPOS, Clever Mazzoni. Curso básico de direito de energia elétrica. Rio de Janeiro: Synergia, 2010.

COIMBRA, Márcio Chalegre. O direito regulatório brasileiro. Revista Jus

Navigandi, Teresina, ano $6, \mathrm{n}^{\circ}$ 51, 01 out. 2001. Disponível

em: <https://jus.com.br/artigos/2076>. Acesso em: 12 set. 2016.

COSTA, Beatriz Souza. Meio ambiente como direito à vida: Brasil, Portugal e Espanha. Belo Horizonte: O Lutador, 2010.

CUÉLLAR, Leila. As agências reguladoras e seu poder normativo. São Paulo: Dialética, 2001.

DI PIETRO, Maria Sylvia et al. Direito regulatório: temas polêmicos. 2. ed. Belo Horizonte: Fórum, 2009.

DIREITO de Energia, Jusbrasil, Salvador, [s./d.]. Disponível em:

<http://www.jusbrasil.com.br/topicos/264132 04/direito-de-energia>. Acesso em: 08 set. 2016.
ENERGIA e meio ambiente. Instituto EDP, São Paulo, [s./d.]. Disponível em: $<$ http://www.edp.com.br/pesquisadoresestudantes/energia/energia-e-meioambiente/Paginas/default.aspx $>$. Acesso em: 08 set. 2016.

FIORILLO, Celso Antônio Pacheco. Curso de direito ambiental brasileiro. 11. ed. São Paulo: Saraiva, 2010.

\section{GUERRA, Sérgio. Organização}

administrativa brasileira: quadro atual e propostas acerca da estruturação de entidades vocacionadas ao desenvolvimento de políticas de estado, não subordinadas ao Poder Público Central. 2011. 275 f. Relatório Final apresentado à Escola Brasileira de Administração Pública e de Empresas EBAPE (Programa de Pós-Doutorado em Administração) - Fundação Getúlio Vargas Escola Brasileira de Administração Pública e de Empresas - Programa de Pós-Doutorado em Administração. Disponível em: <http://bibliotecadigital.fgv.br/dspace/bitstrea $\mathrm{m} /$ handle/10438/10935/Sergio\%20Guerra.pdf ?sequence $=1>$. Acesso em: 12 set. 2016.

JERONYMO FILHO, Miguel. Tipos de energia. oblogtocolando, Botucatu, [s./d.]. Disponível em: $<$ http://espacoeconomicotocolando.blogspot.c om.br/2010/04/tipos-de-energia.html>.

Acesso em: 30 jun. 2016.

LOUBET, Luciano Furtado. Licenciamento ambiental: a obrigatoriedade da adoção das melhores técnicas disponíveis (MTD). Belo Horizonte: Del Rey, 2014.

NOHARA, Irene Patrícia. Direito administrativo. 3. ed. São Paulo: Atlas, 2013.

OLIVON, Beatriz. STJ começa a julgar validade de arbitragem de US\$ 100 milhões. Leite, Tosto e Barros advogados, São Paulo, out. 2015. Disponível em: <http://www.tostoadv.com/stj-comeca-ajulgar-validade-de-arbitragem-de-us-100milhoes-por-beatriz-olivon-ministro-felixfischer-como-disputa-foi-travada-nos-estados- 
unidos-a-corte-especial-do-superior-tribunalde-justi/>. Acesso em: 12 set. 2016.

PIRES, Natália Taves. A principiologia regente do direito ambiental. Âmbito Jurídico, Rio Grande, XI, n. 57, set 2008. Disponível em: <http://www.ambitojuridico.com.br/site/index.php?n_link=revista _artigos_leitura\&artigo_id=5105>. Acesso em: 29 jun. 2016.

ROCHA, Fábio Amorim da; et al. Temas relevantes no direito de energia elétrica. Rio de Janeiro: Synergia, 2012.

SANCHES, Luiz Antonio Ugeda. Curso de direito da energia: da história. São Paulo: Instituto Geodireito. 2011. t. 1.

VASCONCELOS, Keila de Oliveira. Natureza jurídica do bem ambiental. Âmbito Jurídico, Rio Grande, XVIII, $\mathrm{n}^{\circ}$ 135, abr 2015. Disponível em: <http://ambitojuridico.com.br/site/?n_link=revista_artigos_1 eitura\&artigo_id=14846>. Acesso em: 29 jun. 2016. 